\title{
O PROCESSO DE FORMAÇÃO CONTINUADA DOS PROFESSORES DAS SALAS DE RECURSOS MULTIFUNCIONAIS PARA O USO DA TECNOLOGIA ASSISTIVA
}

\author{
Degiane da Silva Farias \\ Mayara de Oliveira Vieira
}

\begin{abstract}
Resumo
O artigo reflete sobre a constituição do processo de formação continuada de professores para o uso da Tecnologia Assistiva - conjunto de equipamentos, recursos e serviços que oferecem condições às pessoas com deficiência para que tenham maior independência e autonomia e, ainda, promovem a inclusão. Pesquisa de abordagem qualitativa, sob os pressupostos de Minayo (2003), e adotando a abordagem exploratórioexplicativa em Leopardi (2002) e Lakatos e Marconi (2011). A coleta de dados empregou o questionário T.A.E e a entrevista semiestruturada. Os dados foram tratados e discutidos com embasamento teórico da análise do conteúdo de Bardin (2010). A formulação teórica baseou-se em Tonolli e Bersch (2006); Libâneo (2001); Machado (2010); Hummel (2015), entre outros. O estudo trouxe como resultado denúncias relacionadas à ausência de materiais pedagógicos, equipamentos e formação voltada para a inclusão e para o uso de novas tecnologias, a exemplo da Tecnologia Assistiva, apontando para a urgência de fortalecer parcerias para a consolidação de um projeto de sociedade inclusiva, cuja marca é educar na diferença e pela diversidade.
\end{abstract}

Palavras-chave: inclusão escolar; Tecnologia Assistiva; formação continuada.

\section{THE PROCESS OF CONTINUING TRAINING OF TEACHERS IN MULTIFUNCTIONAL RESOURCE ROOMS FOR THE USE OF ASSISTIVE TECHNOLOGY}

\begin{abstract}
This paper aims to reflect on how the process of continuing education of teachers has been constituted for the use of assistive technology. assistive technology taken here as the whole set of equipment, resources and services that give people with disabilities conditions to have greater independence and autonomy, and further promote inclusion. this research was built based on the qualitative approach according to the assumptions of Minayo (2003) adopting the exploratory-explanatory type of research in Leopardi (2002) and Lakatos and Marconi (2011). to consolidate the data collection, the T.A.E questionnaire and the semi-structured interview were used. the data were treated and discussed based on the theoretical foundations of content analysis in Bardin (2010). the theoretical formulation was based on authors such as: Tonolli and Bersch (2006); Libâneo (2001); Machado (2010), Hummel (2015) among others. this study resulted in complaints related to the absence of pedagogical materials, equipment and training focused on inclusion and the use of new technologies, such as assistive technology. these notes signify the urgency to strengthen the partnerships necessary to consolidate an inclusive society project that assumes as a mark of educating in difference and diversity.
\end{abstract}

Keywords: school inclusion; assistive technology; continuing education. 


\section{EL PROCESO DE FORMACIÓN CONTINUA DE MAESTROS EN SALAS MULTIFUNCIONALES DE RECURSOS PARA EL USO DE TECNOLOGÍA ASISTIVA}

\section{Resumen}

Este texto propone reflexionar sobre cómo se ha constituido el proceso de educación continua de los docentes para el uso de la tecnología de asistencia. La tecnología de asistencia se toma aquí como un conjunto completo de equipos, recursos y servicios que brindan a las personas con discapacidades condiciones para tener una mayor independencia y autonomía, y promover aún más la inclusión. Esta investigación fue construida en base al enfoque cualitativo de acuerdo con los supuestos de Minayo (2003) adoptando el tipo de investigación exploratoria explicativa en Leopardi (2002) y Lakatos y Marconi (2011). Para consolidar la recopilación de datos, se utilizaron el cuestionario T.A.E y la entrevista semiestructurada. Los datos fueron tratados y discutidos en base a los fundamentos teóricos del análisis de contenido en Bardin (2010). La formulación teórica se basó en autores como: Tonolli y Bersch (2006); Libâneo (2001); Machado (2010), Hummel (2015) entre otros. Este estudio dio lugar a quejas relacionadas con la ausencia de materiales pedagógicos, equipos y capacitación centrados en la inclusión y el uso de nuevas tecnologías, como la tecnología de asistencia. Estas notas significan la urgencia de fortalecer las asociaciones necesarias para consolidar un proyecto de sociedad inclusiva que asume como una marca de educación en la diferencia y la diversidad.

Palabras clave: inclusión escolar; tecnología de asistencia; educación continua.

\section{INTRODUÇÃO}

A década de 1990 do século XX inaugura uma série de profundas transformações na educação brasileira oriundas de reflexões que pautam, entre outras questões, a importância de se investir na formação de professores como mecanismo amplificador do processo educativo. Pela formação de professores se vislumbra um projeto de educação capaz de transitar entre o que se deseja, em termos de sociedade, na relação indissociável com os conhecimentos, saberes, culturas e tecnologias produzidos historicamente.

Esse cenário aponta para a propositura de processos formativos que consubstanciam processos de escolarização que atendam, como direito inviolável, pessoas com necessidades educacionais especiais (NEE) em classes comuns. Assim, com o propósito de garantir a inclusão escolar é demandado o uso de variados dispositivos legais e metodológicos na perspectiva de tornar a escola locus inclusivo de aprendizagem, pautada na diversidade e na diferença como condicionantes próprios da humanidade.

Entre os dispositivos legais aparecem a Lei de Diretrizes e Bases da Educação Brasileira (LDB) n. 9.394/96 que, no Art. 58 explicita: "Entende, por Educação Especial, a modalidade de educação escolar oferecida preferencialmente na rede regular de ensino, para educandos portadores de necessidades especiais" (BRASIL, 1996), assim como a normativa de 2008 que versa sobre a Política Nacional de Educação Especial na Perspectiva da Educação Inclusiva, na qual se recomenda a implementação de políticas públicas voltadas para alunos com deficiência, transtornos globais do desenvolvimento e altas habilidades/superdotação, a fim de que seja garantido o acesso e a permanência com sucesso desses indivíduos nas instituições de ensino regular.

É assegurada, ainda, aos sistemas de ensino, a possibilidade de se organizar na perspectiva de assegurar aos alunos com necessidades educacionais especiais: currículos, métodos, técnicas, recursos educativos, organizações específicas, profissionais especialistas e professores capacitados para garantir o desenvolvimento educacional desses alunos (BRASIL, 1996). 
Ainda no tocante à Lei de Diretrizes e Bases n. 9.394/96, esta designa que os sistemas de ensino têm a responsabilidade de formar dois tipos de profissionais para atuar na educação especial: professores com especialização adequada em nível médio ou superior, para atendimento especializado; bem como, professores do ensino regular capacitados para a integração desses estudantes nas classes comuns (BRASIL, 1996, p. 23).

Como parte desse processo, foi criado o Programa de Implantação de Salas de Recursos por meio da Portaria Normativa n. 13 com dois principais objetivos: a) o primeiro, subsidiar os sistemas de ensino na organização e oferta do atendimento educacional especializado; b) o segundo, contribuir para o fortalecimento do processo de inclusão educacional nas classes comuns de ensino (BRASIL, 2007).

Nesse contexto, o Ministério da Educação (MEC), no ano de 2008, em trabalho conjunto com Secretaria de Educação Continuada, Alfabetização, Diversidade e Inclusão (SECADI) assegurou a prática da implementação de políticas públicas para que alunos com deficiência, transtornos globais do desenvolvimento e altas habilidades/superdotação tivessem garantido o acesso, a participação e o aprendizado nas escolas regulares (BRASIL, 2008).

Entre as prerrogativas dessa política destacam-se aspectos como: a transversalidade da educação especial desde a educação infantil até a educação superior; o atendimento educacional especializado; a continuidade da escolarização nos níveis mais elevados do ensino; a formação de professores para o atendimento; participação da família e da comunidade; acessibilidade urbanística, arquitetônica, nos mobiliários e equipamentos, nos transportes, na comunicação e informação; articulação intersetorial na implementação das políticas públicas (BRASIL, 2008, p. 10, grifo nosso). Todo esse conjunto de diretrizes exige mudanças também no âmbito escolar.

Nas palavras de Vygotsky (1988), ao formular reflexões sobre pessoas com deficiência, assevera sua confiança na possibilidade de essas pessoas se desenvolverem como cidadãos. $\mathrm{O}$ autor referido combate a tendência de entender a deficiência apenas pelo aspecto orgânico e, sobretudo, advoga que o maior empecilho para o desenvolvimento da criança com deficiência não está na sua deficiência de caráter biológico e, sim, nas reservas que o campo social lhe impõe.

Nesse sentido, destaca-se a importância de projetos educacionais que corroborem políticas de inclusão. Autores como Moran (2000), Demo (2004), Valente (1993) discutem a necessidade da formação de professores para o uso de tecnologias na educação, pois de acordo com eles, ensinar e aprender com tecnologias é um desafio que até hoje não foi enfrentado com profundeza. Esse desafio se expande quando se fala de formação continuada de professores para o uso da Tecnologia Assistiva, entendida neste estudo como área de conhecimento de características interdisciplinares e, ainda, todo o arsenal de recursos e de serviços que podem dar condições às pessoas com deficiência de ter maior independência e autonomia e, por conseguinte, promoverem a inclusão (BERSCH, TONOLLI, 2006).

Hummel (2015, p. 124), por meio de um estudo realizado com base na Tecnologia Assistiva, na inclusão e na formação de professores destaca que "[...] a falta de conhecimento inviabiliza a prática de novas formas de atendimento aos alunos", o que impacta diretamente a concretização de processos educacionais inclusivos.

Partindo dessas elucidações e considerando que é cada vez mais presente a inclusão de alunos com necessidades especiais nos sistemas formais de ensino, torna-se urgente fazer reflexões que versem sobre como têm acontecido as formações continuadas de professores das salas de recursos multifuncionais para o uso das Tecnologias Assistivas. De acordo com Caiado, Martins e Antonio (2009), apesar do crescente número de matrículas, nem sempre esse serviço é realizado por um 
docente com formação especializada, o que, para os autores, não tem ajudado no processo de inclusão desejado.

Com base nessas ilustrações, é possível destacar a problemática que direcionou todo o processo de construção deste estudo, qual seja: como ocorre a formação continuada de professores das salas de recursos multifuncionais do Município de Augusto Corrêa - Pará para o uso da Tecnologia Assistiva? Acreditamos que a relevância social e educacional deste estudo centra-se no fato de trazer à tona a urgência da formação continuada de docentes que estão inseridos em salas de recursos multifuncionais, bem como, perceber a necessidade do uso da Tecnologia Assistiva para o processo de inclusão de alunos com deficiência. Igualmente, incorpora nas discussões, em torno da inclusão escolar de alunos com deficiência, outros meios oriundos do que tem sido produzido em termos de instrumentos - fruto do avanço da ciência, representado, nesse campo, pela produção das novas tecnologias.

\section{FUNDAMENTAÇÃO TEÓRICA: TECNOLOGIA ASSISTIVA E INCLUSÃO EDUCACIONAL}

\section{Inclusão educacional}

Com base na Organização Mundial de Saúde (OMS), a Organização das Nações Unidas (ONU) disponibiliza, no sítio oficial da Organização das Nações Unidas no Brasil (ONUBR), dados de 2011 referentes a pessoas com deficiência no mundo. Esses dados destacam que cerca de 1 bilhão de pessoas vivem com alguma deficiência. Os referidos números indicam que uma em cada sete pessoas no mundo apresenta algum tipo de deficiência. A referida Organização chama atenção para o fato de que a falta de estatísticas sobre pessoas com deficiência contribui para a invisibilidade dessas pessoas, o que implica diretamente na concepção e implementação de políticas que exigem planejamento com base em dados concretos.

Outro ponto que merece destaque é o fato de que, segundo a ONUBR, 80\% dos que apresentam alguma deficiência residem em países em desenvolvimento, ou seja, que possuem limitações de ordem social e econômica, a exemplo da garantia de acesso e permanência com sucesso na escola ou, ainda, impossibilidade de custear gastos com serviços de saúde.

Com a finalidade de incentivar a inclusão de alunos com deficiência na escola comum, a Secretaria de Educação Especial/MEC publicou, por meio da Portaria n. 13, de 24 de abril de 2007, o Programa de Implantação de Salas de Recursos Multifuncionais como parte do Plano de Desenvolvimento da Educação (PDE), com o objetivo de apoiar os sistemas de ensino na implantação de salas de recursos multifuncionais, um espaço de Atendimento Educacional Especializado, composto por um arsenal de materiais didático-pedagógicos de acessibilidade, equipamentos e mobiliários.

Entre os objetivos desse Programa no contexto da Política Nacional de Educação Especial na Perspectiva da Educação Inclusiva (BRASIL, 2010), com destaque para o apoio à organização dessa política, evidenciam-se os seguintes: assegurar o pleno acesso dos alunos, público alvo da educação especial, no ensino regular em igualdade de condições com os demais alunos; disponibilizar recursos pedagógicos e de acessibilidade às escolas regulares da rede pública de ensino.

Para o processo de implantação das salas de recursos multifuncionais e de acordo com esses objetivos, o MEC/SEESP se atribui a responsabilidade pelas seguintes ações (BRASIL, 2010):

- aquisição dos recursos que compõem as salas;

- informação sobre a disponibilização das salas e critérios adotados; 
- monitoramento da entrega e instalação dos itens às escolas;

- orientação aos sistemas de ensino para a organização e oferta do AEE;

- cadastro das escolas com sala de recursos multifuncionais implantadas;

- promoção da formação continuada de professores para o AEE;

- encaminhamento, assinatura e publicação dos contratos de doação;

- atualização dos recursos das salas implantadas pelo Programa;

- apoio à acessibilidade nas escolas com salas implantadas.

A distribuição desses espaços se deu a partir das demandas apresentadas pelas secretarias de educação em cada Plano de Ações Articuladas (PAR). Entre 2005 e 2009 foram oferecidas 15.551 salas de recursos multifuncionais, distribuídas em todos os estados e no Distrito Federal, atendidos 4.564 municípios brasileiros $-82 \%$ do total.

Para a implantação destas salas são disponibilizados equipamentos, mobiliários, materiais didáticos e pedagógicos e a oferta de Atendimento Educacional Especializado (AEE), por meio de dois tipos de salas: tipo I e tipo II, conforme especificações técnicas (BRASIL, 2010):

\section{Tabela 1: Especificação dos itens da Sala Tipo I de Recursos Multifuncionais - equipamentos e} materiais didáticos/pedagógicos

\begin{tabular}{|c|c|}
\hline Especificação dos itens da Sala Tipo I: Equipamentos & Materiais Didáticos/Pedagógicos \\
\hline 02 Microcomputadores & 01 Material Dourado \\
\hline 01 Laptop & 01 Esquema Corporal \\
\hline 01 Estabilizador & 01 Bandinha Rítmica \\
\hline 01 Scanner & 01 Memória de Numerais 1 \\
\hline 01 Impressora laser & 01Tapete Alfabético Encaixado \\
\hline 01 Teclado com colmeia Alternativa & 01Software Comunicação \\
\hline 01 Acionador de pressão & 01 Sacolão Criativo Monta Tudo \\
\hline 01 Mouse com entrada para acionador & 01 Quebra-Cabeças - sequência lógica \\
\hline 01 Lupa eletrônica & 01 Dominó de Associação de Ideias \\
\hline Mobiliários & 01 Dominó de Frases \\
\hline 01 Mesa redonda & 01 Dominó de Animais em Libras \\
\hline 04 Cadeiras & 01 Dominó de Frutas em Libras \\
\hline 01 Mesa para impressora & 01 Dominó tátil \\
\hline 01 Armário & 01 Alfabeto Braille \\
\hline 01 Quadro branco & 01 Kit de lupas manuais \\
\hline 02 Mesas para computador & 01 Plano inclinado - suporte para leitura \\
\hline 02 Cadeiras & 01 Memória Tátil \\
\hline
\end{tabular}

Fonte: Manual de Orientação: Programa de Implantação de Sala de Recursos Multifuncionais, 2010

A sala de tipo II contém todos os recursos da sala tipo I, somados os recursos de acessibilidade para alunos com deficiência visual, conforme observa-se na Tabela 2: 
Tabela 2: Equipamentos e materiais didáticos/pedagógicos adicionais da Sala Tipo II

\begin{tabular}{l}
\hline Equipamentos e Materiais Didáticos/Pedagógicos \\
\hline 01 Impressora Braille - pequeno porte \\
01 Máquina de datilografia Braille \\
01 Reglete de Mesa \\
01 Punção \\
01 Soroban \\
01 Guia de Assinatura \\
01 Kit de Desenho Geométrico \\
01 Calculadora Sonoro \\
\hline
\end{tabular}

Fonte: Manual de Orientação: Programa de Implantação de Sala de Recursos Multifuncionais, 2010

De acordo com a relação nominal disponível no portal do MEC, em que consta a lista dos estados e municípios que aderiram ao Programa acima mencionado, o município de Augusto Corrêa iniciou o processo de implantação de salas de recursos multifuncionais no ano de 2008, estendendose até 2013, com o atendimento em nove escolas localizadas na sede do município. Entre essas escolas, foram selecionadas quatro, nas quais realizou-se a pesquisa de campo.

Com base nos objetivos da implementação desses espaços e nas orientações do protocolo de organização das salas, passamos a tratar mais detidamente das discussões acerca da Tecnologia Assistiva como instrumento promotor da inclusão escolar.

\section{Tecnologia Assistiva}

Várias são as dificuldades enfrentadas pelas pessoas com deficiência para exercer sua condição de cidadão, entre elas o fato de depender de outra pessoa para a realização de atividades do dia a dia. Partindo disso, a Tecnologia Assistiva tem-se mostrado como um grande contributo para esses sujeitos, uma vez que o objetivo precípuo do conjunto de ferramentas disponibilizado é, justamente, promover mobilidade e controle de seu ambiente, o que concorre para maior independência. Todavia, cabe o questionamento: o que de fato é Tecnologia Assistiva?

A Tecnologia Assistiva (TA) é uma área do conhecimento de característica interdisciplinar. De acordo com Bersch; Tonolli (2006), o termo é consideravelmente novo, empregado para identificar todo o arsenal e serviços que contribuem para proporcionar ou ampliar habilidades funcionais de pessoas com deficiência e, consequentemente, promover vida independente e inclusão.

É também definida como uma ampla gama de equipamentos, serviços, estratégias e práticas concebidas e aplicadas para amenizar problemáticas enfrentadas pelos indivíduos com deficiências.

No sentido de ampliar a discussão sobre essa área do conhecimento, a Secretaria Especial dos Direitos Humanos da Presidência da República (SEDH/PR), por meio da Portaria n. 142, de 16 de novembro de 2006, instaurou o Comitê de Ajudas Técnicas (CAT), reunindo um grupo de especialistas brasileiros e representantes de órgãos governamentais com a proposição de fomentar uma agenda de trabalho.

O objetivo desse Comitê foi apresentar propostas de políticas governamentais e parcerias entre a sociedade civil e órgãos públicos referentes à área de Tecnologia Assistiva; estruturar diretrizes da área de conhecimento; detectar centros regionais de referência, objetivando a formação de rede nacional integrada; estimular, nas esferas federal, estadual, municipal, a criação de centros de 
referência; propor a criação de cursos na área de Tecnologia Assistiva; bem como o desenvolvimento de outras ações, com o objetivo de formar recursos humanos qualificados e propor a elaboração de estudos e pesquisas relacionados com o tema da Tecnologia Assistiva.

Assim, tendo por base os documentos de legislação e apoiado em referenciais de outros países, o CAT aprovou, em 14 de dezembro de 2007, a denominação de Tecnologia Assistiva, que subsidiasse políticas públicas brasileiras. Tal denominação explicita:

Tecnologia Assistiva é uma área do conhecimento, de característica interdisciplinar, que engloba produtos, recursos, metodologias, estratégias, práticas e serviços que objetivam promover a funcionalidade, relacionada à atividade e participação de pessoas com deficiência, incapacidades ou mobilidade reduzida, visando sua autonomia, independência, qualidade de vida e inclusão social (BRASIL, SDHPR, Comitê de Ajudas Técnicas, ATA VII).

Ainda de acordo como o referido Comitê, os recursos da Tecnologia Assistiva são classificados em categorias, tendo em vista os objetivos funcionais a que se destinam. Ressalta-se que a classificação em que se apoia esse estudo foi formulada em 1998 por José Tonolli e Rita Bersch. Recentemente foi utilizada pelo Ministério da Fazenda, de Ciência, Tecnologia e Inovação e pela Secretaria Nacional de Direitos Humanos da Presidência da República quando da publicação da Portaria Interministerial n. 362, de 24 de outubro de 2012, que trata sobre a linha de crédito subsidiado para aquisição de bens e serviços de Tecnologia Assistiva destinados a pessoas com deficiência, e sobre o rol de bens e serviços.

No contexto educacional, com base nos pressupostos de Bersch (2008), a Tecnologia Assistiva surge como uma metodologia propícia e significativa, pois engloba desde recursos simples e de custo reduzido — favorecendo a utilização em sala de aula, de acordo com as especificações de cada aluno com necessidades especiais —, até inovadores e criativos softwares que visam à acessibilidade a autonomia.

O aspecto mais importante na escolha da Tecnologia Assistiva, de acordo com Hogetop e Santarosa (2002), é a necessidade de avaliação das potencialidades dos alunos perante a utilização de um determinado recurso, com o objetivo de ser utilizado, de fato, para melhorar suas habilidades e, principalmente, seu processo de inclusão em sociedade.

Nesse contexto, a Tecnologia Assistiva é o suporte necessário e eficaz para um atendimento tecnológico e especializado que garanta resultados positivos, pois a TA aparece com a capacidade de desenvolver e incluir, com qualidade, alunos com várias especificidades.

Para Sassaki (1996, p. 1) a Tecnologia Assistiva “[...] é destinada a dar suporte (mecânico, elétrico, eletrônico, computadorizado etc.) a pessoas com deficiência física, visual, auditiva, mental ou múltipla". Nessa perspectiva, nota-se que essa tecnologia atinge diversas áreas que vão desde recursos pedagógicos adaptados a recursos de acessibilidade ao computador e recursos para atividades da vida diária, como adaptações de jogos e brincadeiras, além de equipamentos de auxílio às pessoas cegas e/ou com baixa visão.

De acordo com Pelosi (2003), a Tecnologia Assistiva contempla incontáveis áreas como a comunicação suplementar e/ou alternativa e adequações de acesso ao computador; equipamentos de auxílio para visão e audição; controle do meio ambiente; adaptação de jogos e brincadeiras, adaptações de postura sentada, mobilidade alternativa, próteses e a integração dessa tecnologia nos diferentes ambientes como casa, escola e local de trabalho.

$\mathrm{Na}$ visão desses teóricos, qualquer ferramenta improvisada caracteriza o uso de Tecnologia Assistiva, conforme salienta Manzini (2005, p. 82): 
Os recursos de Tecnologia Assistiva estão muito próximos do nosso dia a dia. Ora eles nos causam impacto devido à tecnologia que apresentam, ora passam quase despercebidos. Para exemplificar, podemos chamar de Tecnologia Assistiva uma bengala, utilizada por nossos avós para proporcionar conforto e segurança no momento de caminhar, bem como um aparelho de amplificação utilizado por uma pessoa com surdez moderada ou mesmo veículo adaptado para uma pessoa com deficiência.

O referido autor chama a atenção para o fato de que o uso adequado desses recursos só tem contribuído para o processo de inclusão social e educacional. Assim, tanto no que se refere às discussões teóricas quanto no campo da prática, esse conceito "[...] vem conquistando um espaço importante na educação especial no Brasil, e, nos últimos anos pôde-se observar o aumento significativo de estudos sobre a temática (HUMMEL, 2015, p. 36).

\section{A formação continuada dos professores para o uso das Tecnologias Assistivas}

Libâneo (2001) advoga que o professor só edifica sua profissionalidade no exercício concreto do seu trabalho. Nesse sentido, a escola é apontada como o locus por excelência onde o docente tem as condições e a oportunidade de fazer vir à tona saberes e habilidades fundamentais para o sucesso do ensino. A fala desse autor nos remete à ideia de que as brechas deixadas tanto na formação inicial como na formação continuada desses sujeitos vão produzir, negativamente, reflexos na qualidade do processo ensino-aprendizagem.

A formação de professores tem sido foco de debates de grandes autores como Gatti (2010, 2011), Pimenta (2011), Tardif (2002); Veiga (2002); André (2010), Brzezinski (2008), Scheibe (2010). A partir desses e de outros estudiosos têm sido discutidas, na temática da formação de professores, questões como identidade docente, valorização profissional, saberes docentes, política de formação, bem como vicissitudes que atravessam processos de formação de professores.

Um primeiro ponto quando se trata da temática formação de professores, diz respeito à necessidade do reconhecimento da pluralidade de sujeitos que coexistem no espaço escolar. Esse reconhecimento dá condições para a construção de práticas pedagógicas que contemplem a todos, pois nas palavras de Hummel (2015, p. 23): “O reconhecimento das especificidades dos alunos com necessidades especiais é visto no sentido de compreender as características das deficiências e possibilitar experiências de aprendizagem adequadas ao aluno".

Para tanto, segundo o referido autor, isso propõe uma reestruturação do processo ensino aprendizagem em todos os seus aspectos. No tocante à formação inicial é latente a urgência de reformulação em muitos elementos dos cursos de licenciatura, no currículo, nas disciplinas, nos conteúdos, nas atividades desenvolvidas e mais a necessidade de articulação entre todos esses elementos, pois “"...] preparar-se para atuar numa sociedade em que muito se discute sobre a Educação Inclusiva é buscar constantemente uma formação adequada” (HUMMEL, 2015, p. 24).

Nesse sentido, Gatti (2010) vai dizer que, tendo em vista as inúmeras transformações do cenário atual é preciso que exista uma proposta curricular de formação do profissional da educação em que se prime pela inter-relação entre teoria e prática, ou seja, uma práxis. Segundo essa autora, é urgente e necessário assegurar aos futuros docentes condições de compreensão da realidade das escolas e, também, fundamentação teórica consistente.

Ao encontro dessa proposição, Veiga (2002) afirma que a formação inicial deve dar condições ao aluno, futuro profissional, de ter um desenvolvimento que contemple os aspectos científico, cultural, social e pedagógico. No que se refere à formação continuada, deve buscar problematizar as 
situações vividas pelos professores. Para essa autora, pensar em formação do professor é pensar na unidade entre formação inicial e continuada, pois "[...] associa-se o conceito de formação de professores à inconclusão do homem. A formação identifica-se com a ideia de percurso, processo, trajetória de vida pessoal e profissional. Por isso a formação não se conclui, ela é permanente" (VEIGA, 2002, p. 16).

Outro autor que tem se debruçado sobre a ideia de formação do professor, seja a inicial, seja a continuada é Maurice Tardif (2002). Segundo ele, o professor em seu trabalho movimenta uma multiplicidade de saberes: os saberes da formação profissional, relativos às ciências da educação e das ideias pedagógicas; os saberes disciplinares, oriundos das disciplinas específicas; os saberes curriculares, relativos ao trato com o programa escolar; e os saberes experienciais, oriundos da experiência profissional individual e da socialização no trabalho.

Ainda para este autor, os saberes construídos pelos professores são diversificados, mas também correspondem a uma construção temporal, ou seja, são pensados e construídos por meio da aprendizagem e da socialização que os docentes conhecem ao longo de sua vida pessoal e profissional. Em outras palavras, são construções fomentadas em tempos sociais diferentes: tempo da infância, da escola primária, da formação profissional, da entrada na profissão, da carreira e outros (TARDIF, 2002).

No tocante à formação de professores para o uso da Tecnologia Assistiva, acreditamos na necessidade de esses profissionais estarem aptos para o uso dessas ferramentas, caso contrário, de nada adiantará esse arsenal de serviços e mobiliários estarem dispostos nas escolas. De acordo com Demo (2004), o maior desafio do professor, no uso das tecnologias digitais, está em transformar as informações em conhecimentos para os alunos.

Nesse mesmo sentido, Emer (2011) afirma que, nos dias atuais, é parte do trabalho docente o uso das tecnologias e das informações, contudo, é preciso, antes de tudo, dar significado a elas para que façam sentido aos alunos e tenham conexão com suas realidades. Todo esse movimento exige um processo de formação continuada docente.

Apoiamo-nos nas formulações de Emer (2011) para tratarmos da formação continuada dos professores das Salas de Recursos Multifuncionais. A autora nos chama a atenção para a importância do trabalho dos profissionais desses espaços como contributo para o processo de inclusão nas salas regulares: "[...] acreditamos que também seja papel do professor articular a inclusão do seu aluno em todo o contexto escolar" (EMER, 2011, p. 85).

Em termos legais, de acordo com a Resolução n. 4 de 2 de outubro de 2009, Art. 12 (p. 3), "[...] o professor deve ter formação inicial que o habilite para o exercício da docência e formação específica para educação especial", e no tocante à atuação profissional nas Salas de Recursos Multifuncionais, essa mesma Resolução destaca a importância da formação, para que exista a possibilidade de oferecer Atendimento Educacional Especializado de qualidade. Hummel (2012) explica que essa Resolução não deixa claro se formação docente para atuar nesses espaços deve acontecer mediante a formação inicial ou como processo de formação continuada.

Nas palavras de Hummel (2015, p. 34), “[...] o acúmulo de funções que o professor de AEE assume dentro do contexto escolar influencia na construção de sua identidade profissional. Esse professor passa a vivenciar os mesmos anseios do professor da sala de aula regular". 


\section{CAMINHOS METODOLÓGICOS}

A escolha de um caminho metodológico a ser trilhado demanda um grande desafio, uma vez que o paradigma no qual se sustenta um trabalho de investigação demonstra o lugar de onde fala o pesquisador. Esse estudo configura uma pesquisa com base no enfoque qualitativo, uma vez que não está preocupada com questões relacionadas à representatividade numérica, mas, sim, com a compreensão que possuem os professores das salas de recursos multifuncionais no que tange ao uso de Tecnologias Assistivas. De acordo com Minayo (2003, p. 10), "O estudo qualitativo pretende apreender a totalidade coletada visando, em última instância, atingir o conhecimento de um fenômeno histórico que é significativo em sua singularidade".

Optamos pela abordagem qualitativa, pelo fato de trazer em seu arcabouço a perspectiva da valorização da fala, dos sentidos, da percepção dos sujeitos sobre os fenômenos em que estão inseridos. Nessa abordagem, os objetivos ganham outras dimensões e amplitude, buscam-se compreender os processos existentes por meio de uma aproximação direta entre pesquisador e objeto de estudo.

Tendo em vista a escolha da abordagem supracitada, o movimento posterior consistiu na seleção do tipo de pesquisa em que se sustentaria esse estudo. Assim, com base nos três grandes eixos que a abordagem qualitativa assinala - pesquisa descritiva, pesquisa exploratória, pesquisa explicativa - denominamos este trabalho como do tipo exploratório-explicativo.

Fazemos uso das explicações de Leopardi (2002) para denominá-la exploratória, uma vez que, segundo a autora referida, esse tipo de pesquisa favorece maior aproximação entre pesquisador e objeto ou fenômeno pesquisado, além de ajudar na apreensão de determinada realidade em seus vários aspectos.

No tocante à ideia de uma pesquisa do tipo explicativa, recorremos às formulações das autoras Lakatos e Marconi (2011) que destacam não só a possibilidade de registrar dados ou fatos, mas de analisá-los, interpretá-los na perspectiva de melhor compreendê-los. Nesse mesmo sentido, Severino (2007, p. 123) ressalta que a pesquisa explicativa "[...] além de registrar e analisar os fenômenos estudados busca identificar suas causas".

A presente pesquisa teve como contexto o município de Augusto Corrêa, situado no Nordeste do estado do Pará. Sua população estimada, em 2017, era de aproximadamente 44.734 pessoas, de acordo com dados estatísticos do Instituto Brasileiro de Geografia e Estatística (IBGE, 2010).

A seleção dos participantes teve início a partir de pesquisa no Departamento de Estatística da Secretaria Municipal de Educação (SEMED), com o objetivo de saber quais as escolas localizadas na área urbana do município que possuíam sala de recurso multifuncional, assim como a quantidade total de alunos com deficiência no sistema municipal.

Diante das primeiras informações, foi definida a participação de cinco professores lotados em salas de recursos multifuncionais. Esse quantitativo representava mais da metade de profissionais que estavam lotados nesses espaços pedagógicos na sede da cidade de Augusto Corrêa. Pode-se dizer que o critério utilizado para participação foi que todos atuassem como professores nas salas de recursos multifuncionais em alguma das nove escolas de educação infantil e de ensino fundamental localizadas na área urbana do município, e que fossem responsáveis pelo processo de aprendizagem de alunos com deficiência.

No sentido de obedecer aos cuidados éticos da pesquisa científica, nos apoiamos na Resolução n. 196/96 que destaca: “[...] sob a ótica do indivíduo e da coletividade, [são estes] os quatros referenciais básicos da bioética: autonomia, não maleficência, beneficência e justiça" (BRASIL, 1996, 
p. 61). Nesse sentido, foi disposto a todos um Termo de Consentimento Livre e Esclarecido (TCLE), convidando-os a participar, ou não, da pesquisa. Após a livre adesão, o referido Termo foi assinado.

Como instrumento de coleta de dados e procedimento de levantamento, foram utilizadas algumas questões do Questionário T.A.E (Tecnologia Assistiva para a Educação) desenvolvido por Manzini, Maia e Gaspareto (2008) e a entrevista semiestruturada.

Quanto ao uso do Questionário, o objetivo foi traçar o perfil social, econômico e profissional dos sujeitos da pesquisa. De acordo com Gil (1999), existem dois grandes benefícios no uso dessa técnica: o primeiro, consiste na apreensão de informações de grande número de indivíduos; e o segundo diz respeito à possibilidade de apreensão de informações tanto dos sujeitos como da realidade na qual estão inseridos. No caso desse estudo, as duas proposições elencadas pelo referido autor foram percebidas no decorrer do processo.

Realizaram-se entrevistas, a partir de um roteiro semiestruturado, com professores das salas de recursos multifuncionais da Secretaria Municipal de Educação de Augusto Corrêa. Nas palavras de Gil (1999, p. 128) o roteiro de entrevista se caracteriza por ser uma técnica de obtenção de dados de campo que, ao ser constituído por um conjunto de perguntas, tem o intuito de coletar informações sobre a identidade, interesses, conceitos e expectativas de um indivíduo ou de um determinado grupo de pessoas. Desse modo, no estudo em questão, esta técnica teve o objetivo de levantar informações sobre como vem se dando a formação continuidade de docentes das salas de recursos multifuncionais, a partir de suas próprias percepções.

A análise de dados foi feita com base nos pressupostos de Bardin (2011), por meio da técnica de análise de conteúdo, observando-se as três etapas: pré-análise; exploração do material; tratamento dos dados e interpretação. A pré-análise tem como finalidade a organização dos dados, por meio da escolha dos documentos e da leitura flutuante. Na exploração do material realiza-se a codificação ou categorização dos dados. No tratamento dos resultados é possível, por parte do pesquisador, fazer inferências e interpretações.

\section{RESULTADOS E DISCUSSÃO}

Nesta seção, apresentamos e analisamos os dados que consubstanciam o cumprimento dos objetivos traçados nesta pesquisa, tratados a partir de cinco temáticas analíticas, a saber: Temática analitica 1: Perfil socioprofissional dos professores participantes da pesquisa; Temática analítica 2: Formação continuada dos professores do Município de Augusto Corrêa/PA para o uso da Tecnologia Assistiva; Temática analítica 3: Responsáveis pela formação continuada no município de Augusto Corrêa; Temática analítica 4: Principais dificuldades no trabalho com alunos com deficiência e Temática analítica 5: Significado de ser professor de alunos com deficiência. 
Com base nos dados produzidos verificamos que as cinco participantes são do sexo feminino, todas já acima dos 30 anos, distribuídas em três faixas etárias, como mostra a Tabela 3; quatro se assumem como pardas e apenas uma como amarela. São mulheres que, do ponto de vista do estado civil, constituem três grupos: duas no grupo de solteiras; duas no grupo de divorciadas; e uma no grupo de casadas.

No que tange ao tempo de atuação profissional na educação, quatro têm mais de 10 anos de atuação; todavia esse tempo não se mostra da mesma maneira quando referente ao tempo de atuação na educação especial. Essa disparidade de tempo pode ser explicada pela própria história da educação especial no Brasil. Infelizmente, é recente a conquista da matrícula de pessoas com alguma deficiência nas escolas. Por muito tempo instituições especializadas assumiram a função assistencialista no trato com a educação especial.

Entre as professoras participantes da pesquisa verificamos que as cinco possuem Ensino Superior — todas em Pedagogia. Uma delas, além dessa formação, também é graduada em Educação Física. Em nível de Pós-Graduação lato sensu, ou seja, especialização, quatro delas já vivenciaram essa formação continuada; todavia, desse total, apenas três especializações estão diretamente vinculadas ao atendimento de alunos com deficiência. Nesse caso, duas questões chamam atenção: a primeira, o fato de que existe uma professora sem nenhuma formação específica em nível de pós-graduação para atuar em salas multifuncionais; a segunda, o fato de que uma delas tem formação de especialista voltada para outra dimensão do processo educativo.

Em relação a cursos de curta duração, ficou evidente que Braille e Libras são as formações mais comuns, com três participantes. A Tecnologia Assistiva aparece com apenas uma participante, assim como a voltada a deficiências múltiplas. Se considerarmos que as escolas recebem alunos com inúmeras outras deficiências, faz-se necessário que os cursos de curta duração sejam, cada vez mais variados em termos de possibilidade de atendimento à diversidade de alunos com deficiência na escola. Chama atenção, também, o fato de a Tecnologia Assistiva não aparecer com a intensidade que acreditávamos, o que implica apontar, à SEMED de Augusto Corrêa, a necessidade de fortalecer a formação com base nessa tecnologia, uma vez que ela contribui para que o professor se municie de meios para atender as mais variadas situações de deficiência que ocorrem no interior das escolas.

Com base nas primeiras variáveis, destacamos o papel fundamental da formação, para pensarmos processos inclusivos no contexto escolar. Esse papel é demandado tanto na LDB n. 9.394 de 1996, quanto na Política Nacional de Educação Especial na perspectiva da educação inclusiva (2008). Além da base legal, Hummel (2015) reafirma a necessidade da formação para que os professores tenham condições de oferecer processos educativos pautados na inclusão que, segundo ela, demandam a necessidade de nos cercarmos de aparatos, a exemplo da Tecnologia Assistiva.

Pelo que está posto na literatura atual, a formação de professores deve ser assumida como parte indissociável de um projeto de educação desejante de libertação, de implicação social, política, ética e cultural da escola, capaz de promover verdadeiras revoluções que consubstanciam a dignidade de pessoas humanas, expressa não só pelo direito de acessar e permanecer na escola com sucesso, mas de viver em plenitude sua humanidade, independentemente de qualquer condicionante físico e/ou cognitivo que possa representar limitação.

A Tabela 3, que se apresenta a seguir, sintetiza as informações referentes às cinco professoras que participaram da pesquisa e que expressam parte do seu perfil socioprofissional. Dizemos parte por reconhecer que essas variáveis não são as únicas implicadas diretamente na definição do retrato 
de um grupo de profissionais, pois existem outras, a exemplo das questões econômicas, culturais, ideológicas etc. que também contribuem para percebermos como um indivíduo se constitui em um determinado grupo de pertencimento, no caso desse estudo, pertencimento profissional.

Tabela 3: Perfil socioprofissional

\begin{tabular}{|c|c|}
\hline Sexo & Feminino -5 \\
\hline Faixa etária & $\begin{array}{l}\text { Entre } 30 \text { e } 40 \text { anos }-2 \\
\text { Entre } 41 \text { e } 50 \text { anos }-2 \\
\text { Entre } 51 \text { e } 60 \text { anos - } 1\end{array}$ \\
\hline Cor/etnia & $\begin{array}{l}\text { Parda }-4 \\
\text { Amarela }-1\end{array}$ \\
\hline Estado Civil & $\begin{array}{l}\text { Solteira }-2 \\
\text { Divorciada }-2 \\
\text { Casada }-1\end{array}$ \\
\hline Tempo de atuação no magistério & $\begin{array}{l}\text { De } 1 \text { a } 10 \text { anos }-1 \\
\text { De } 11 \text { a } 20 \text { anos }-3 \\
\text { De } 21 \text { a } 30 \text { anos }-1\end{array}$ \\
\hline Tempo de atuação com alunos com deficiência & $\begin{array}{l}\text { De } 1 \text { a } 5 \text { anos }-1 \\
\text { De } 6 \text { a } 10 \text { anos }-4\end{array}$ \\
\hline Formação & $\begin{array}{l}\text { Graduação - } 5 \\
\text { Pós-Graduação lato sensu - } 4\end{array}$ \\
\hline Cursos de Formação em nível de graduação & $\begin{array}{l}\text { Pedagogia }-5 \\
\text { Outra licenciatura - } 1 \text { (Educação Física) }\end{array}$ \\
\hline Relação da Pós-graduação & $\begin{array}{l}\text { Com Educação Inclusiva - } 3 \\
\text { Com Educação - } 1\end{array}$ \\
\hline Cursos de Formação Continuada & $\begin{array}{l}\text { Braille }-3 \\
\text { Libras - } 3 \\
\text { Deficiências Múltiplas - } 1 \\
\text { Tecnologia Assistiva }-1 \\
\text { Obs.: Professoras fizeram mais de um curso, é o } \\
\quad \text { que demonstra esta célula. }\end{array}$ \\
\hline
\end{tabular}

Fonte: Construído pela autora (VIEIRA, 2018).

Quando pensamos na formação de professores, pensamos também em questões como condições de trabalho. Nessa questão não têm sido raras as denúncias apresentadas em relação à falta de condições para exercer a profissão, a partir de pesquisas realizadas no contexto da escola básica. Os estudos de Gatti (1997, 2010, 2011) assim como de Scheibe (2010) são representativos desse debate.

Com base nas respostas das cinco participantes da pesquisa, elaboramos um quadro síntese que mostra, de um lado, outros recursos que frequentemente são utilizados pelas professoras da sala funcional e, do outro lado, recursos e/ou equipamentos que as professoras sentem falta nesse espaço, e que poderiam ser utilizados no dia a dia escolar. No que se refere a outros recursos utilizados, ficou evidente que as professoras buscam meios alternativos, o que, na nossa avaliação, estão relacionados não só à necessidade de buscar, de pesquisar como parte do processo, mas também à própria carência de materiais considerados, por elas, fundamentais para o atendimento de alunos com deficiência, como vemos na Tabela 4. 
Tabela 4: Recursos presentes/ausentes na sala multifuncional

\begin{tabular}{|c|c|}
\hline \begin{tabular}{|l|} 
Outros recursos que \\
frequentemente são utilizados pelos \\
professores da sala multifuncional
\end{tabular} & $\begin{array}{l}\text { Recursos e/ou equipamentos que os professores sentem falta na } \\
\text { sala multifuncional, que poderiam ser utilizados no dia a dia } \\
\text { escolar }\end{array}$ \\
\hline 1. Texto fatiado & 1. Computador (3 ocorrências) \\
\hline 2. Dados & 2. Notebook (1 ocorrência) \\
\hline 3. Bolso com números em libras & 3. Espaço (1 ocorrência) \\
\hline 4. Palavras com gravuras & 4. Globo terrestre adaptado (2 ocorrências) \\
\hline 5. Alfabeto em libras & 5. Equipamentos eletrônicos - DVD, TV (2 ocorrências) \\
\hline 6. Jogo da memória de frutas & 6. Prancheta para leitura (1 ocorrência) \\
\hline 7. Recortes visuais para & 7. Regletes de mesa e punções (1 ocorrência) \\
\hline comportamentos & 8. Scanner com voz (1 ocorrência) \\
\hline 8. Prancha do seu nome & 9. Guias de assinatura (1 ocorrência) \\
\hline 9. Engrossadores de lápis & 10. Kit de desenho geométrico geoplano (1 ocorrência) \\
\hline 10. Jogo de multiplicação & 11. Máquina de datilografia Braille (1 ocorrência) \\
\hline 11. Jogo de sílabas & 12. Mouse estático de esfera (1 ocorrência) \\
\hline 12. Alfabeto ilustrado de madeira & $\begin{array}{l}\text { 13. Livros adaptados com sinais de comunicação (1 ocorrência) } \\
\text { 14. Calculadora sonora (1 ocorrência) } \\
\text { 15. Colecão de literatura Libras/Português. }\end{array}$ \\
\hline
\end{tabular}

Fonte: Produção da autora (VIEIRA, 2018).

As questões referentes a recursos nos fazem pensar ainda que, embora exista um protocolo definido em legislação (BRASIL, 2010) que apresenta especificações dos itens que devem estar contidos em salas multifuncionais, existem duas problemáticas referentes a esses itens. Uma é referente à manutenção e, a outra, é quanto à reposição dos itens. Infelizmente, no Brasil, as políticas de aquisição de material não possuem planejamento que garanta manutenção e reposição. De modo geral, as escolas recebem equipamentos e fazem usufruto até que esse material deixe de funcionar por apresentar algum problema que demande assistência técnica. Apesar de as escolas receberem recursos por meio do Programa Dinheiro Direto na Escola (PDDE), com rubricas específicas para reparos, ainda assim não são suficientes para as inúmeras demandas dessa natureza.

Temática analítica 2: formação continuada dos professores do município de Augusto Corrêa/PA para o uso da Tecnologia Assistiva

Quando questionadas sobre como e em qual período têm se dado os processos de formação continuada de professores do município de Augusto Corrêa/PA para o uso de Tecnologia Assistiva, as professoras apresentaram uma linha temporal que vai de 2012 até 2017. Todavia, a professora KCFS destaca, em relação à Tecnologia Assistiva, uma formação vaga, o que para nós produz duas frentes de reflexões. Uma delas é de que a formação não está atingindo os professores como devia; a outra é que, sendo a Tecnologia Assistiva uma força em potencial de auxílio aos professores, deveria ser assumida enquanto objeto de formação com maior afinco pela SEMED. Em relação à ocorrência das formações e como são concebidas pelos professores que passaram por elas, verificamos algumas unidades de sentido que endossam o que destacamos no início da temática.

Através de encontros presenciais de formação continuada desde 2012. (Prof ${ }^{a}$. KGPC).

No período de 2015, em três meses. (Prof ${ }^{\mathrm{a}}$. MJRM).

Apenas em 2014. (Profa. MRFR). 
Em 2014 houve uma formação. Porém foi uma formação vaga, principalmente para os professores que ainda não tem domínio da tecnologia. (Prof ${ }^{a}$. KCFS).

Esse ano não houve formação para esse fim, no entanto houve outras finalidades. (Prof ${ }^{a}$. OFA).

Essas unidades de sentido nos permitem reafirmar que, tanto encontros presenciais periódicos de formação atrelados a demandas da rede municipal de ensino relacionadas ao atendimento de alunos com deficiência, quanto a eficiência desses encontros formativos devem ser assumidos como política educacional em nível municipal, sem perder de vista o que está estabelecido em termos de direito, tanto em nível internacional quanto nacional.

Temática analítica 3: responsáveis pela formação continuada no município de Augusto Corrêa

Com relação aos responsáveis pelo direcionamento da formação continuada dos professores das salas de recursos multifuncionais em Augusto Corrêa, as professoras participantes da pesquisa apontam que tanto a Secretaria Municipal de Educação como o Centro de Atendimento Educacional Especializado são as duas grandes referências, porém, aparecem nesse cenário, alguns parceiros, a exemplo da Universidade Federal Rural da Amazônia (UFRA) e da Associação de Pais e Amigos dos Excepcionais (APAE), como veremos nas unidades de sentido a seguir.

Secretaria Municipal de Educação (SEMED) e Centro de Atendimento Educacional Especializado (CAEE). (Prof ${ }^{a}$. KGPC).

A Secretaria de Educação em parceria com a Universidade Federal Rural da Amazônia (UFRA). (Prof ${ }^{a}$. MJRM).

O Centro de Atendimento Especializado (CAEE). (Prof ${ }^{a}$. MRFR).

Sempre que ocorre a formação continuada quem direciona é a coordenadora da educação especial, a última formação foi ministrada por um professor da UFRA. (Profa ${ }^{a}$ KCFS). Palestrantes de outras instituições como APAE. (Prof ${ }^{a}$. OFA).

Esse ponto referente aos responsáveis e colaboradores, por meio da presença da UFRA, assim como da APAE, como parceiras, expressa o movimento que tem dado a tônica em relação aos desafios enfrentados pelas SEMEDs, em geral, para lidar com as problemáticas da educação. Em relação à Educação Inclusiva, os debates internacionais promovidos pela ONU e pelo Fundo das Nações Unidas para a Infância (UNICEF) assim como os debates nacionais a partir de estudos como os de Sassaki (1996), Emer (2011) e Hummel (2015) reafirmam a necessidade de ações coletivas, solidárias e comprometidas com a inclusão de cada indivíduo que compõe a sociedade planetária.

Os apontamentos desses autores nos levam a crer que não é possível vislumbrar uma sociedade inclusiva sem que todos estejam implicados nesse processo. As mais de um bilhão de pessoas que atualmente apresentam algum tipo de deficiência no mundo são responsabilidade de todos nós. Nosso compromisso ético, social e político, próprio da nossa humanidade denota um esforço como sociedade para vencer os desafios de pessoas com deficiência, frente à inclusão escolar ou de outras ordens. 


\section{Temática analítica 4: principais dificuldades no trabalho com alunos com deficiência}

No que concerne às principais dificuldades, as professoras ressaltam a questão da carência de material pedagógico e de equipamentos necessários. Esse é um ponto que já demos ênfase nas discussões a partir da Tabela 3, na temática que versa sobre o perfil socioprofissional das professoras. Além desses desafios, aparecem outros relacionados à dificuldade de parceria entre professores das salas multifuncionais e professores das salas regulares; à parceria com as famílias; à diversidade de alunos em termos de deficiência na sala de atendimento educacional especializado; ao preconceito e ao domínio do Braille e da Libras como instrumentos fundamentais no processo de inclusão, como veremos nas unidades de sentido a seguir:

Dificuldade na parceria com o professor de sala regular e a carência de materiais pedagógicos devido à diversidade de alunos no AEE. (Prof ${ }^{a}$. KGPC).

A falta de parceria com a família, transporte escolar, entre outros. (Prof ${ }^{a}$. MJRM).

Não ter equipamentos necessários para desenvolver as habilidades apresentadas pelos alunos. (Prof ${ }^{a}$. MRFR).

São tantas as dificuldades, mas as que me deixam mais angustiada é a falta de equipamentos adequados para trabalhar com meus alunos, a falta de conhecimento de algumas tecnologias, o preconceito de outros profissionais. (Prof ${ }^{a}$. KCFS).

Falta de domínio em Braille e Libras, pois essas comunicações requerem estar praticando no cotidiano. (Profa. OFA).

Em relação à dificuldade de parceria entre professores das salas multifuncionais e professores das salas regulares, bem como a parceria com as famílias, chamamos atenção para o que já apresentamos como defesa, neste texto, quando nos referimos às parcerias necessárias para que, de fato, práticas sociais e da escola possam se efetivar. A presença de limitações em termos de parceria representa também limitações em relação à concretização de um projeto de sociedade que, por excelência, é multissetorial, interdisciplinar, multicultural.

Questionamo-nos quanto a limitações dessa natureza. Os descompassos existentes produzem descaminhos em relação ao que podemos conseguir em termos de inclusão escolar de alunos com deficiência. Portanto, temos que acreditar e fortalecer, cada vez mais, um sentido de ação colaborativa, cooperativa, solidária.

No que tange à diversidade de alunos em termos de deficiência na sala de atendimento educacional especializado, podemos dizer que esse cenário apresenta duas questões: de um lado, que a escola tem acolhido alunos independentemente da situação de deficiência, o que para nós representa que temos feito nossa lição de casa enquanto sociedade; por outro lado, de que esse cenário demanda, cada vez mais, investimentos para que professores sejam capacitados para atender a essa diversidade, pois como destacam Caiado, Martins e Antonio (2009), embora as matrículas de alunos com deficiência em escolas regulares tenham sido ampliadas, essa ampliação não segue no mesmo ritmo quando a questão é formação especializada para atender esse público.

Nesses termos, os apontamentos de Hummel (2015), assim como de Moran (2000), Demo (2004), Valente (1993) nos ajudam a fortalecer a bandeira da formação de professores para o uso da tecnologia na educação como prerrogativa da inclusão - formação que seja expressão de investimentos que potencializem o exercício da docência para a inclusão.

Nas falas das professoras fica evidente a importância do uso de novas tecnologias a partir da Tecnologia Assistiva, no processo educativo e de inclusão escolar de alunos com deficiência, como se observa nas unidades de sentido a seguir: 
A Tecnologia Assistiva é uma ferramenta necessária para o trabalho do professor do AEE. É onde o professor juntamente com o aluno vão tentar facilitar o aprendizado do educando através do uso dessas tecnologias. (Prof ${ }^{a}$. MJRM).

É muito importante para minha prática, é uma grande aliada que dá suporte ao meu aluno e me ajuda na ruptura de aloumas barreiras que impedem a participação dos meus alunos no ensino regular. (Prof ${ }^{\mathrm{a}}$. KCFS).

Embora Libras e Braille se mostrem como focos de maior investimento nos últimos anos na formação de professores, ainda assim as professoras participantes destacaram que as formações não têm sido suficientes para que dominem a contento o uso da língua e da linguagem, respectivamente, como instrumentos fundamentais no processo de inclusão.

Um grande desafio, evidente tanto nas falas das professoras como também nos estudos que se voltam para discutir educação especial e inclusão escolar, é a questão do preconceito que, para nós é um ponto que está no núcleo dos desafios enfrentados tanto pelos professores, quanto pela escola e a sociedade como um todo. É justamente o preconceito aliado à falta de formação que têm produzido situações de exclusão social e escolar. Essa pauta deve ser nosso ponto de partida e de chegada em relação a qualquer proposição que uma secretaria de educação venha apresentar em prol da inclusão escolar de alunos com deficiência.

Precisamos admitir que somos impregnados por práticas preconceituosas, que provocam situações de marginalização, exclusão, humilhação e que, portanto, nos levam a negligenciar o outro como sujeito de direito (BRASIL, 1996). Só assim poderemos rever nossas práticas e assumir uma postura de respeito às diferenças.

Essa postura está diretamente interligada ao modo como concebemos nossa condição de sujeito no mundo e, por consequência, de profissionais. Sobre essa questão, trataremos a seguir como ponto de chegada de exercício de produção do conhecimento científico.

\section{Temática analítica 5: significado de ser professor de alunos com deficiência}

Quando nos lançamos à aproximação com o sentido que as professoras atribuem a ser professor de alunos com deficiência, verificamos que esse sentido está vinculado a questões como dedicação para atender cada sujeito na sua especificidade; missão de ajudar o outro a aprender, a se desenvolver; sonhar junto com o outro um sonho de dias melhores, de conquistas maiores; enfrentamento de desafios de conhecer, de agir; rompimento de barreiras relacionadas a outrem e às próprias professoras; desafios de atrelar, no exercício da profissão, a prática da investigação; de enfrentar processos de exclusão, de não se acovardar. A seguir, verificamos a expressão desses sentidos mencionados:

Dedicaşão intensa, pois cada aluno tem sua especificidade, necessitando uma diversidade de recursos e conhecimentos para atender essa demanda [...]. (Prof ${ }^{a}$. KGPC).

É uma missão muito gratificante poder ajudar alguém; que para muitas pessoas o aluno com deficiência não aprende, [...] precisamos sonhar com algo melhor para o aluno que é desenvolvimento das habilidades necessárias de acordo com sua limitação para uma vida em sociedade, rompemos desafios, barreiras, mas superamos quando vemos a criança escrever o seu primeiro nome, falar bom dia, boa tarde etc. (Prof ${ }^{a}$. MJRM).

É uma experiência sem explicaşão, pois nos transmite harmonia mesmo com (deficiência) dificuldades a partir do momento que você vai conhecendo a especificidade de cada aluno. (Prof ${ }^{a}$. MRFR). 


\begin{abstract}
Ser professor de alunos com deficiência para mim é ser um investigador, pois o trabalho com esses alunos exige que esteja sempre lendo, sempre investigando de que maneira meu aluno aprende, quais os comprometimentos deles nas áreas de linguagem, raciocínio lógico, memória e quais metodologias eu posso usar para que eu consiga desenvolver as potencialidades deles. Posso dizer também que quem se compromete com a educação especial tem que ser corajoso e desafiador. (Prof ${ }^{a}$. KCFS).

Significa estar superando desafios de aprendizagem e contribuindo com a formacão de alunos que muitas vezes são excluídos. (Profa. OFA).
\end{abstract}

Os sentidos atribuídos pelas professoras representam, a nosso ver, muito do que vimos tratando em termos de inclusão. Embora todo aparato tecnológico e formação sejam fundamentais para que se avance na direção de um espaço escolar inclusivo, isso não se dá fora de sujeitos que assumem, no seu modo de existir, princípios ético-políticos e sociais implicados com a totalidade, com uma ideologia do acolhimento, da incorporação, da adição, que enfrente as práticas do menos um, menos dois, menos muitos.

É necessário enfrentarmos menos o caráter biológico das deficiências e mais as reservas no campo social impostas a quem, por alguma razão, foi acometido por alguma deficiência (VYGOTSKY, 1988). Assegurar o direito ao acesso e permanência na escola em condições iguais (BRASIL, 1996, 2010) deve ser apropriado como demanda própria de uma sociedade que se assume democrática e que se quer igualitária e com vocação para a equidade. Uma sociedade que garanta a máxima de Santos (2003, p. 127) de que se tem direito à igualdade "[...] quando a nossa diferença nos inferioriza; e temos o direito de sermos diferentes quando nossa igualdade nos descaracteriza. Daí a necessidade de uma igualdade que reconheça as diferenças e de uma diferença que não produza, alimente ou reproduza as desigualdades".

\title{
CONSIDERAÇÕES FINAIS
}

Ao enveredarmos em um exercício de análise de como se dá a formação continuada dos professores de salas de recursos multifuncionais para uso da Tecnologia Assistiva no município de Augusto Corrêa/PA, percorremos processos de reflexão que vão desde a aproximação com questões de natureza legal que disciplinam o atendimento de alunos com deficiência, até reflexões oriundas de discussões que têm sido travadas em nível nacional e internacional.

Esse primeiro exercício nos permitiu ter acesso a discursos oficiais relacionados à garantia de direitos, assim como a discursos que denunciam limitações da sociedade para lidar com a garantia desses direitos.

Com base nos dados produzidos a partir da pesquisa de campo, verificamos que, no caso de Augusto Corrêa, não é diferente em relação àquilo que lhes falta como requisito para o exercício da profissão docente junto a alunos com deficiência, pois as professoras participantes da pesquisa também adotam discursos nessa direção. Dentre as ausências, materiais pedagógicos, equipamentos e formação aparecem com muita evidência.

Além dessas ausências, as professoras salientam também os desafios frente a dificuldades de parceria entre docentes de salas multifuncionais e professores das salas regulares, bem como de parceria com as famílias. Esse é o ponto que precisamos retomar como força, porque como já mencionamos anteriormente, a formação e condições de trabalho não são suficientes para garantirmos o atendimento com dignidade a cada aluno - garantido por lei. 
Nesse cenário, a Tecnologia Assistiva aparece como contributo da inclusão de alunos com deficiência, todavia, de acordo com as professoras participantes da pesquisa, ainda não é fato consumado no município de Augusto Corrêa. É preciso que o município fortaleça suas ações em torno da formação de professores, agregando não só a Tecnologia Assistiva, mas todas as tecnologias e aparatos técnico-procedimentais capazes de municiar professoras e professores na tarefa de educar na diferença e pela diversidade.

A tarefa de educar na diferença e pela diversidade implica uma dose significativa da capacidade de compreender a individualidade de cada sujeito, compreensão essa que demanda fortalecer a utopia do sonho coletivo por dias melhores, felizes, que são a expressão do nosso comprometimento ético, político e social, e que nos leva a assumir a postura de intransigência e enfrentamento frente ao preconceito, à exclusão ou a qualquer conduta que expresse negação do direito de todos e de cada um na sua particularidade, no contexto de uma sociedade tão plural e diversa como a nossa.

\section{REFERÊNCIAS}

ANDRÉ, Marli. Formação de professores: a constituição de um campo de estudos. Educação, Porto Alegre, v. 33, n. 3, set./dez. 2010, p. 174-181. Disponível em: http://caioba.pucrs.br/faced/ojs/index.php/faced/article/view/8075/5719. Acesso em: 10 mar. 2018.

BARDIN, Laurence. Análise de conteúdo. São Paulo: Edições 70, 2011.

BERCH, Rita. Introdução à Tecnologia Assistiva. CEI. Centro Especializado em Desenvolvimento Infantil. Porto Alegre, 2006.

BRASIL. Manual de Orientação: Programa de Implantação de sala de recursos multifuncionais. Brasília, $2010 . \quad$ Disponível em: http://portal.mec.gov.br/index.php?option $=$ com docman\&view $=$ download\&alias $=9936$-manualorientacao-programa-implantacao-salas-recursos-multifuncionais\&Itemid=30192. Acesso em: 20 mar. 2018.

BRASIL. MEC. Lei de Diretrizes e Bases da Educaşão Nacional - LDB n. 9394/96. Brasília, 20 dez. 1996.

BRASIL. Política Nacional de Educação Especial na perspectiva da educação inclusiva. Brasília, 2008. Disponível em: http://portal.mec.gov.br/arquivos/pdf/politicaeducespecial.pdf. Acesso em: 10 mar. 2018.

BRASIL. Portaria Normativa $n^{\circ} 13$, de 24 de abril de 2007. Disponível em: http: $/ /$ portal.mec.gov.br/index.php?option $=$ com docman \&view $=$ download\&alias $=9935$-portaria13-24-abril-2007\&Itemid=30192. Acesso em: 5 fev. 2018.

BRASIL. Subsecretaria Nacional de Promoção dos Direitos da Pessoa com Deficiência. Comitê de Ajudas Técnicas. Tecnologia Assistiva. Brasília, 2006.

BRZEZINSKI, Iria. Políticas contemporâneas de formação de professores para os anos iniciais do ensino fundamental. Cedes. v. 29 n. 105 set./dez. 2008. Disponível em: http://www.cedes.unicamp.br/rev_apresentacao.htm . Acesso em: 15 fev. 2018.

CAIADO, Katia Regina Moreno; MARTINS, Larissa de Sousa; ANTONIO, Nicole Dragone Rosseto. A educação especial em escolas regulares: tramas e dramas do cotidiano escolar. Revista Diálogo Educação, v. 9, n. 28, set.-dez., 2009. p. 621-632.

DEMO, Pedro. Universidade, aprendizagem e avaliação: horizontes reconstrutivos. Porto Alegre: Mediação, 2004. 
EMER, Simone de Oliveira. Inclusão Escolar: formação docente para o uso das TICs aplicada como Tecnologia Assistiva na sala de recurso multifuncional e a sala de aula. Dissertação (Mestrado). Universidade Federal do Rio Grande do Sul, Faculdade de Educação, Programa de Pós-Graduação em Educação, Porto Alegre, Rio Grande do Sul, 2011.

FONSECA, João J. S. Metodologia da pesquisa cientifica. Fortaleza: UEC, 2002. (Mimeo).

GATTI, Bernardete A. Formação continuada de professores: a questão psicossocial. In: GATTI, Bernardete A. Educadora e pesquisadora. Belo Horizonte: Autêntica, 2011.

GATTI, Bernardete. A. Formação de professores no Brasil: características e problemas. Educação e Sociedade, Campinas, v. 31, n. 113, out.-dez. 2010. Disponível em: http://www.scielo.br/pdf/es/v31n113/16.pdf . Acesso em: 25 fev. 2018. p. 1355-1379

GIL, Antônio Carlos. Métodos e técnicas de pesquisa social. 5. ed. São Paulo: Atlas, 1999.

HOGETOP, Luisa; SANTAROSA, Lucila Maria Costi. Tecnologias assistivas: viabilizando a acessibilidade ao potencial individual. Informática na Educação: teoria \& prática, Porto Alegre: v. 5, n. 2, nov. 2002. p. 103-118.

HUMMEL, Eromi Izabel. Tecnologia Assistiva: a inclusão na prática. Curitiba, Paraná: Appris, 2015.

LAKATOS, Eva Maria; MARCONI, Marina Andrade. Fundamentos de metodologia cientifica. 5. ed. São Paulo: Atlas, 2011.

LEOPARDI, Maria Tereza. Metodologia da pesquisa na saúde. Santa Maria, Rio Grande do Sul: Palotti, 2002.

LIBÂNEO, José Carlos. Organização e gestão da escola. Teoria e prática. 3. ed. Goiânia: Alternativa, 2001. MACHADO, Rosangela; BERSCH, Rita. Tecnologias Assistivas - TA: aplicações na educação. Santa Maria: UFSM, 2010.

MANZINI, Eduardo José; GASPARETTO, Maria Elisabete Rodrigues Freire; MAIA, Shirley Rodrigues. Questionário TAE - Tecnologia Assistiva para Educação. Brasília, Distrito Federal, 2008.

MANZINI, Eduardo José. Tecnologia Assistiva para educação: recursos pedagógicos adaptados. p. 82-86. In: Ensaios pedagógicos: construindo escolas inclusivas. Brasília: SEESP/MEC, 2005.

MINAYO, Maria Cecília de Sousa (org.). Pesquisa social: teoria, métodos e criatividade. Petrópolis: Vozes, 2003.

MORAN, José Manuel; MASSETTO, Marcos; BEHRENS, Marilda. Novas tecnologias e mediação pedagógica. São Paulo: Papirus, 2000.

NÓVOA, António. Os professores e sua formação. Lisboa: Dom Quixote, 1992.

NÓVOA, António. Profissão professor. Porto: Ed. Porto: 1991.

ORGANIZAÇÃO DAS NAÇÕES UNIDAS NO BRASIL. Disponível em: https://nacoesunidas.org/acao/pessoas-com-deficiencia/. Acesso em: 2 out. 2017.

PELOSI, Miryan Bonadiu. A comunicação alternativa e ampliada nas escolas do Rio de Janeiro: formação de professores e caracterização dos alunos com necessidades educacionais especiais. p. 183187. In: Anais. Seminário internacional sociedade inclusiva. PUC Minas. Belo Horizonte, 2003.

PIMENTA, Selma Garrido. Formação de professores: saberes da docência e identidade do professor. Disponível em: http://revista.fct.unesp.br/index.php/Nuances/article/view/50/46. Acesso em: 25 fev. 2018. 
RADABAUGH, Mary Pat. NIDRR's Long Range Plan - Tecnology for Access and Function Research Section Two. NIDDR Research Agenda Chapter 5: Technology for access and function. Disponível em: http://www.ncddr.org/rpp/techaf/lrp ov.html. Acesso em: 16 fev. 2018.

SANTOS, Boaventura de Sousa. Reconbecer para libertar: os caminhos do cosmopolitanismo multicultural. Rio de Janeiro: Civilização Brasileira, 2003.

SASSAKI, Romeu. Porque o termo Tecnologia Assistiva? 1996. Disponível em: http://www.cedionline.com.br/ta.html. Acesso em: 10 set. 2017.

SCHEIBE, Leda. Valorização e formação dos professores para a educação básica: questões desafiadoras para um novo Plano Nacional de Educação. p. 7-31. Cedes. v. 25, n. 112, jul.-set. 2010. Disponível em: http://www.cedes.unicamp.br/rev apresentacao.htm. Acesso em: 15 fev. 2018.

TARDIF, Maurice. Saberes docentes e formação profissional. 4. ed. Rio de Janeiro: Vozes, 2002.

VALENTE, José Armando. Diferentes usos do computador na educação. In: VALENTE, José Armando (org.). Computadores e conhecimento: repensando a educação. Campinas: Gráfica da UNICAMP, 1993.

VEIGA, Ilma Passos de Alencastro (org.). Perspectivas para a formação do professor hoje. In: ENDIPE 11, 2002, Goiânia. Anais... Goiânia: (s. ed.), 2002. 1 CD-ROM.

VYGOTSKY, Lev Semyonovich et al. Linguagem, desenvolvimento e aprendizagem. São Paulo: Ícone, 1988. ZEICHNER, Kenneth. Formando professores reflexivos para a educação centrada no aluno: possibilidades e contradições. In: BARBOSA, Raquel Lazzari (org.). Formação de educadores: desafios e perspectivas. São Paulo: UNESP, 2003.

Submetido em outubro 2019. Aprovado em janeiro 2020.

\section{Informações das autoras}

Degiane da Silva Farias

Doutora em Educação pelo Programa de Pós-Graduação em Educação pela Universidade Federal do Pará, Professora Substituta UFPA/Campus Bragança/PA.

E-mail:degi20ane@hotmail.com

ORCID: https://orcid.org/0000-0002-3280-0550

Link Lattes: http://lattes.cnpq.br/2996317268837531 
Mayara de Oliveira Vieira

Mestranda no Programa de Pós-Graduação de Criatividade e Inovação em Metodologias de Ensino Superior/UFPA

E-mail:may bsi@yahoo.com.br

ORCID: https://orcid.org/0000-0001-5392-2242

Link Lattes: http://lattes.cnpq.br/4849296736177942 